\title{
Chirality and the origin of atmospheric humic-like substances
}

\author{
I. Salma ${ }^{1}$, T. Mészáros ${ }^{1}$, W. Maenhaut ${ }^{2}$, E. Vass ${ }^{1}$, and Z. Majer ${ }^{1}$ \\ ${ }^{1}$ Eötvös University, Institute of Chemistry, Budapest, Hungary \\ ${ }^{2}$ Ghent University, Institute for Nuclear Sciences, Ghent, Belgium
}

Received: 2 September 2009 - Published in Atmos. Chem. Phys. Discuss.: 24 September 2009

Revised: 13 January 2010 - Accepted: 14 January 2010 - Published: 5 February 2010

\begin{abstract}
Aerosol water extracts and atmospheric humiclike substances (HULIS) obtained from $\mathrm{PM}_{2.5}$-fraction aerosol samples collected in a rural/continental background environment and in an urban environment in spring and summer, and at a tropical site that was heavily impacted by biomass burning were studied. HULIS was obtained as the water-soluble, methanol-elutable material isolated from a solid-phase extraction procedure. The mean organic matter-to-organic carbon mass conversion factor and the standard deviation of $2.04 \pm 0.06$ were derived for HULIS from biomass burning. Mean atmospheric concentrations of HULIS for the rural and urban environments and for the biomass burning during daylight periods and nights, were $1.65,2.2,43$, and $60 \mu \mathrm{g} \mathrm{m}^{-3}$, respectively. This and other abundances indicate that intense emission sources and/or formation mechanisms of HULIS operate in biomass burning. Mean contributions of $\mathrm{C}$ in HULIS (HULIS-C) to watersoluble organic carbon (WSOC) were 35, 48, 63, and 76\%, respectively, for the sample set listed. HULIS-C is the major component of the WSOC in tropical biomass burning. The data also suggest that HULIS most likely do not share common origin in the three environments studied. Differentiation among the possible formation processes was attempted by investigating the optical activity of HULIS through their (electronic and vibrational) circular dichroism properties. The urban HULIS did not show optical activity, which is in line with the concept of their major airborne formation from anthropogenic aromatics. The rural HULIS revealed weak optical activity, which may be associated with one of their important formation pathways by photo-oxidation and oligomerisation, i.e., with the formation from chiral biogenic precursors with one of the enantiomers slightly enriched. The The biomass burning of HULIS exhibited a strong effect in the vibrational
\end{abstract}

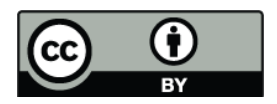

Correspondence to: I. Salma (salma@chem.elte.hu) circular dichroism as a clear distinction from the other two types. This was related to the contribution of the thermal degradation products of lignins and cellulose. The biomass burning of HULIS resemble Suwannee River Fulvic Acid standard more closely in some aspects than the urban and rural types of HULIS, which may be related to their common origin from plant material.

\section{Introduction}

Aerosol particles containing atmospheric HUmic-LIke Substances (HULIS) can play an important role in continental environments (Fuzzi et al., 2006). They act as cloud condensation nuclei since HULIS make up a major mass fraction of the continental fine-sized water-soluble organic compounds (Salma et al., 2007, and references therein). HULIS also influence the formation, water activation or equilibrium of cloud or fog droplets in the air (McFiggans et al., 2006; Dinar et al., 2006; Asa-Awuku et al., 2007; Wex et al., 2007; Ziese et al., 2008) by affecting their surface tension (Facchini et al., 1999; Kiss et al., 2005; Salma et al., 2006; Topping et al., 2007) and water activity of the droplets (Varga et al., 2007). In addition, HULIS are coloured and interact directly with the sunlight (Dinar et al., 2008). Furthermore, their amphiphilic properties cause aggregation above a critical concentration leading to solubilization of other aerosol constituents (Tabazadeh, 2005; Salma et al., 2008) including some trace elements with biological role.

Atmospheric humic-like substances are regarded to be a supramolecular system of multi-component organic compounds and oligomers that exhibits many properties similar to those of humic matter (Graber and Rudich, 2006, and references therein). They contain aromatic rings and aliphatic lateral chains with carboxyl, hydroxyl, carbonyl or methoxy terminal groups. They are defined operationally and are sometimes called organic macromolecules (Zappoli

Published by Copernicus Publications on behalf of the European Geosciences Union. 
et al., 1999; Samburova et al., 2005b) or macromolecular polycarboxylic acids (PA) (Decesari et al., 2000). The existing isolation or separation methods are believed to yield largely overlapping generic classes of compounds. HULIS, isolated from aerosol samples collected in diverse environments of the world or seasons, exhibit somewhat different properties (Blazsó et al., 2003; Kiss et al., 2005). Furthermore, spontaneous change in the aggregation and conformational states of HULIS can take place under changing solution conditions and, therefore, uniform properties for such a complex mixture cannot always be expected (Salma and Láng, 2008). These conceptual and experimental disadvantages largely complicate their study.

Despite their potential importance, our knowledge on the formation of the fine-sized HULIS is still lacking. Several formation processes were proposed on the basis of atmospheric and smog chamber experiments. They include both primary emissions and chemical reaction pathways in gaseous and/or condensed phases. Biomass burning was recognized as a major primary source of HULIS via the incomplete breakdown of polymeric plant matter, or recombination and direct condensation of low-molecular-mass primary combustion products (Zappoli et al., 1999; Facchini et al., 2000; Graham et al., 2002; Mayol-Bracero et al., 2002). About $33 \%$ of all plant matter is made up of cellulose; wood as an important form of biomass is composed of cellulose (40-50\% of dry mass), hemicelluloses (20-30\% of dry mass), lignins (20-30\% dry mass) and extraneous matter (extractives and ash, $4-10 \%$ of dry mass; Simoneit et al., 1999). Cellulose occurs as polysaccharide macromolecules consisting of a long linear chain of several hundred to over ten thousand linked $\mathrm{C}_{6} \mathrm{H}_{10} \mathrm{O}_{5}$ units. Hemicelluloses are mixtures of polysaccharides with much shorter and branching chains, and are less structured. Lignins are phenolic polymers produced primarily from hydroxycinnamyl alcohols, e.g., p-coumaryl, coniferyl and sinapyl alcohols. During wood combustion, cellulose decomposes in two alternative ways. The first pathway (flaming combustion) occurs at temperatures $>300^{\circ} \mathrm{C}$, and is related to bond cleavage by transglycosylation, fission and disproportionation reactions resulting in tarry anhydro-sugars and volatile products which are rapidly oxidized in the flame. The second pathway (smouldering combustion) dominates at temperatures $<300^{\circ} \mathrm{C}$, and involves depolymerisation, water elimination, fragmentation and oxidation, and leads to char formation and emits large amounts of incomplete oxidized pyrolysis products with low vapour pressure. Cellulose has chirality, which means that its molecules can theoretically exist in two distinct forms (mirror images which are referred to as enantiomers) that are distinguishable by their interaction with polarized light. Cellulose, produced by biosynthesis, is only built from $\beta$ D-glucopyranose units, which endows the natural cellulose and its derivatives with very strong optical activity. HULIS, formed via the thermal degradation of cellulose in biomass burning, are expected to maintain this chirality and to show optical activity. The burning of lignins mainly produces acid, aldehyde, ketone and alkyl derivatives of phenols into the smoke. Lignins are considered not to be optically active in the UV/Vis region (Ralph et al., 1999) and, therefore, their derivatives produced by burning are also not expected to exhibit substantial optical activity in this spectral range.

Formation mechanism of secondary HULIS - which can make up a major or dominant component of secondary organic aerosol (SOA, see below) - generally involves photochemical reactions of volatile organic compounds (VOCs) in the gas phase followed by oligomerisation of some low volatile products (Claeys et al., 2004a, b; Kroll and Seinfeld, 2008). There is also indirect evidence of the HULIS formation by heterogeneous reactions of unsaturated gas-phase compounds on particle surfaces in the presence of acids (Jang et al., 2002; Limbeck et al., 2003; Gao et al., 2004), or by incloud processing (Gelencsér et al., 2003; Hoffer et al., 2004). Compounds that contribute to the oligomerisation can originate from both biogenic and anthropogenic sources (Gao et al., 2004; Iinuma et al., 2004; Kalberer et al., 2004; Baltensperger et al., 2005). In forested areas, isoprene, monoterpenes and sesquiterpenes are the most abundant biogenic VOCs (they make up 55\% of the biogenic VOCs emitted into the global atmosphere; Guenther et al., 1995). The two latter compound classes have large aerosol yield and, hence, they are important precursors to oligomerisation (Hoffmann and Warnke, 2007) leading to secondary HULIS as well. Isoprene has no chirality, while many of the relevant monoterpenes are chiral compounds. The (-)-form of the dominant monoterpene, $\alpha$-pinene (accounting for approximately 50\% of all monoterpenes) was measured in large excess, relative to its (+)-form over and within a tropical forest, while the reverse was observed over a boreal forest consisting primarily of Scots pine (Williams et al., 2007). The relative enrichment of one of the two enantiomer precursors could be reflected in the optical activity of secondary HULIS as well, since both enantiomers react with $\mathrm{OH}$ radical and $\mathrm{O}_{3}$ at the same reaction rate (Nunes et al., 2005).

In cities, it is the vehicles that contribute notably to the atmospheric concentrations of VOCs. Road traffic mainly emits ethane, propane and aromatics (e.g., benzene, toluene, ethyl benzene and xylenes). The latter group of compounds contains important or possibly the dominant precursors of SOA (Atkinson, 2000; Hoffmann and Warnke, 2007), which includes secondary HULIS as a major component. Acid catalyzed reactions of aldehydes or ketones on the surfaces of or inside the particles are also able to form oligomers (Hoffmann and Warnke, 2007). These concepts are also backed by ambient/field observations. It was estimated, for example, that HULIS contributed up to $55 \%$ of SOA in the $\mathrm{PM}_{2.5}$-size fraction in an urban environment in spring, and a positive sampling artifact (measured by a tandem filter method as the mean concentration ratio for HULIS-C on the back and front filters) of $17 \%$ derived for urban HULIS also indicates that the secondary formation pathways are considerable in cities 
(Salma et al., 2007). Significant correlation between photochemical activity and atmospheric HULIS concentration in summer also confirms their secondary formation (Limbeck and Puxbaum, 1999; Samburova et al., 2005b). Atmospheric oxidation of soot particles with $\mathrm{O}_{3}$ also produces HULIS (Decesari et al., 2002). The latter formation can only account for a certain part of HULIS since the products did not resemble all of the properties reported for atmospheric HULIS. It is expected that urban HULIS do not show a substantial optical activity since their expected major precursors are not chiral, and even if some of the precursors are optically active, the chemical reactions (especially the radical-assisted reactions, which are typical) in the air yield racemic mixtures with no optical activity.

All emission and formation processes overviewed above can be operative in an environment, but their intensity and extent can vary for different environments or different seasons. Secondary HULIS can be generated on the surface of existing aerosol particles which contain primary HULIS and HULIS from heterogeneous mechanisms and chemical aging as well and, therefore, the emission sources and various formation processes become difficult to recognize and quantify separately. A comparative study on the optical activity through the circular dichroism of HULIS isolated from aerosol samples collected in rather different environments including a rural/continental background site, an urban environment and a tropical site heavily impacted by biomass burning, can, however, provide new information on their origin. It can also give us further clues for identifying the major emission source types and for understanding the basic formation processes of HULIS.

\section{Experimental}

\subsection{Samples and sample treatment}

The rural/continental background aerosol samples were collected at K-puszta (latitude $46^{\circ} 58^{\prime} \mathrm{N}$, longitude $19^{\circ} 35^{\prime} \mathrm{E}$, altitude $125 \mathrm{~m}$ above mean sea level, m.s.l.) on the Great Hungarian Plain approximately $80 \mathrm{~km}$ southeast of Budapest, and $15 \mathrm{~km}$ northwest of the nearest town Kecskemét. The site was located on a clearing within a mixed forest $(62 \%$ coniferous and 28\% deciduous trees) including 10\% grassland. Two daily collections were conducted on 4 May and 6 May 2008 with a KS-300 high volume aerosol sampler equipped with a $\mathrm{PM}_{2.5}$ pre-separator (Kalman System, Hungary) and operated at an air flow rate of $530 \mathrm{~L} \mathrm{~min}^{-1}$. Whatman QM-A quartz fibre filters were used as the collection substrate. The filters were pre-baked at $650^{\circ} \mathrm{C}$ for $8 \mathrm{~h}$ before sampling, in order to remove possible organic contaminants. The exposed area of the filters was $154 \mathrm{~cm}^{2}$.

The urban aerosol sample was collected in central Budapest (at Széna Square, latitude $47^{\circ} 37.4^{\prime} \mathrm{N}$, longitude $19^{\circ} 1.7^{\prime} \mathrm{E}$, altitude $114 \mathrm{~m}$ above m.s.l.) from 3 to
10 June 2008 for one week. The site is heavily influenced by vehicular traffic. The aerosol sample and a field blank filter were taken with a DHA-80 high-volume aerosol sampler equipped with a $\mathrm{PM}_{2.5}$ pre-separator (Digitel Elektronik, Switzerland) and operated at an air flow rate of $500 \mathrm{~L} \mathrm{~min}^{-1}$. Whatman QM-A quartz fibre filters were used as collection substrate. The filters had been pre-baked at $550^{\circ} \mathrm{C}$ for $12 \mathrm{~h}$ before sampling. The exposed area of the filters was $154 \mathrm{~cm}^{2}$.

The biomass burning aerosol samples were collected at a pasture site (latitude $10^{\circ} 45.7^{\prime} \mathrm{S}$, longitude $62^{\circ} 21.5^{\prime} \mathrm{E}$, altitude $315 \mathrm{~m}$ above m.s.l.) in the Amazon Rainforest, state of Rondônia, Brazil, during the LBA-SMOCC field campaign (e.g., Decesari et al., 2006). The samples that are dealt with in the present study were taken from 18 to 22 September 2002 separately over daylight periods (from about $07 \mathrm{~h} 45$ through $17 \mathrm{~h} 45 \mathrm{LT}$ - local time $-\mathrm{LT}=\mathrm{UTC}-4$ ) and night (from about $18 \mathrm{~h} 30$ through 07h00 LT). The biomass burning activity was reported to be the most intensive during this period of the campaign (Decesari et al., 2006). The samples were collected with a high-volume dichotomous virtual impactor on Gelman Pallflex front and back quartz fibre filters in series. The filters were pre-baked at $550^{\circ} \mathrm{C}$ for $24 \mathrm{~h}$ prior to sampling. The exposed area of the filters was $61.5 \mathrm{~cm}^{2}$. $\mathrm{PM}_{2.5}$-size fraction aerosol samples collected on the front filters in the high-flow air stream at a flow rate of $300 \mathrm{~L} \mathrm{~min}^{-1}$ were used for the present research. Altogether, five samples for the daylight periods, five samples for nights and two field blank filters were obtained during the days specified above.

The aerosol samples were placed in pre-baked $\mathrm{Al}$ foils, and were kept in the freezer until further treatment. The two samples collected at the rural site were treated together. Of the aerosol samples collected at the biomass burning impacted site, one quarter of each filter was processed for the present study. The filter sections for the daylight periods were treated together, and the filter sections for the nights were also processed together. The samples were utilized for isolation of water-soluble HULIS by a one-step solid-phase extraction (SPE) method (Varga et al., 2001; Kiss et al., 2002; Salma et al., 2008). In short, the filters were cut into pieces and the extraction was carried out with high-purity reagent Milli$\mathrm{Q}$ water with occasional stirring and hand-shaking at room temperature for $36 \mathrm{~h}$. The filter-water system was allowed to stand for $30 \mathrm{~min}$ at the end of the extraction procedure. The water extracts were filtered through a $0.22 \mu \mathrm{m}$ syringe PVDF membrane filter (Millipore, USA) to remove the filter debris and suspended insoluble particles. The $\mathrm{pH}$ of the filtrates was adjusted to 2 with $\mathrm{HCl}$, and HULIS were separated by pre-conditioned SPE columns (Oasis HLB, Waters, USA). The retained organics were eluted with methanol, and the eluents were first combined and then subdivided into several aliquots. The aliquots were evaporated to dryness with nitrogen stream. The mass of the resulting HULIS aliquot samples was measured by gravimetry at a stabilized temperature $\left(20^{\circ} \mathrm{C}\right)$ and relative humidity $(50 \%)$. The samples were 
pre-equilibrated at these conditions for several hours. Hygroscopic uptake of water by HULIS is substantial at considerably higher relative humidities (Wex et al., 2007; Ziese et al., 2008). The weighing was repeated one day later after the samples had been placed into a drying chamber with a temperature of $40^{\circ} \mathrm{C}$ for $1 \mathrm{~h}$. The samples were kept in the refrigerator until further dissolution.

The presence of inorganic salts in considerable amounts in the HULIS fraction was excluded earlier (Kiss et al., 2002; Emmenegger et al., 2007; Salma et al., 2007). However, it was demonstrated (Limbeck et al., 2005; Emmenegger et al., 2007; Stone et al., 2009) that some carboxylic acids and oxysubstituted aromatic compounds, e.g., succinic, adipic, hydroxybenzoic, lactic, trifluoroacetic, n-hexanoic, n-octanoic, cis-pinonic, phenylacetic, methylphthalic, cyclopentanedicarboxylic, butanedioic, heptanedioic, octanedioic, tricarballylic, benzenetricarboxylic and benzenetetracarboxylic acids, and some known biomass burning compounds including guaiacol, vanillin, acetovanillone and syringaldehyde (Saxena and Hildemann, 1996; Schauer et al., 2001; Decesari et al., 2006) could appear in the HULIS-containing eluent. These compounds are fortunately achiral and, therefore, they do not contribute to the investigated optical activity. They are generally in small amounts and, therefore, their effect on the bulk characteristics of HULIS was negligible. Nevertheless, the biases associated with the isolation method should definitely be studied further to quantify their exact contribution.

Some aliquots of the HULIS samples were dissolved in Milli-Q water, and the solutions were utilised for electronic circular dichroism (ECD) spectrometry and UV absorbance measurement without any treatment. Other HULIS aliquots were dissolved in acetone with a volume of 150-500 $\mu \mathrm{l}$, and the solutions were utilised to prepare thin films for vibrational circular dichroism (VCD) spectrometry and IR absorbance measurement. Approximately $20 \mu \mathrm{l}$ of the HULIS solution in acetone was carried on a window plate made of $\mathrm{CaF}_{2}$ as a droplet, it was dried at room temperature, and the procedure was repeated two or three times at the same location of the plate in order to reach reasonable absorbance values. Sample spots with a typical diameter of 5-7 mm were obtained in this way. Of the biomass burning HULIS samples, two aliquots obtained for the daylight periods only were investigated by ECD and VCD methods. Suwannee River Fulvic Acid (SRFA, code 2S101F, abundance of C is $52.34 \%$, International Humics Substances Society, based in USA) standard was used for comparative purposes, since several previous studies referred to it as representative of atmospheric HULIS. The SRFA standard was dissolved in Milli-Q water and was measured without any treatment, or it was dissolved in acetone to prepare a thin film.

\subsection{Measuring methods and data treatment}

The ECD spectra and UV absorbance were recorded with a Jasco J-810 spectropolarimeter (Japan) in the wavelength interval from 200 to $280 \mathrm{~nm}$ and from 260 to $400 \mathrm{~nm}$ in a nitrogen atmosphere. Cuvettes made of quartz windows, and with path lengths of $d=0.2,0.1$ or $0.02 \mathrm{~cm}$, were used. Baseline correction for the ECD was achieved by subtracting the spectrum recorded for the solvent under the identical experimental conditions. The ECD data were recorded in ellipticity $(\theta)$ which were converted to molar circular dichroism $(\Delta \varepsilon)$ defined as the differential molar extinction coefficient for the left-handed circularly polarized light $\left(\varepsilon_{L}\right)$ and for the right-handed circularly polarized light $\left(\varepsilon_{R}\right)$ according to the equation:

$\Delta \varepsilon \equiv \varepsilon_{L}-\varepsilon_{R}=\frac{1}{c d}\left(A_{L}-A_{R}\right)=\frac{\theta}{c d k}$,

where $c$ is the molar concentration, $A_{L}$ and $A_{R}$ are the absorbance for the left- and right-handed circularly polarized light, and $k$ is an aggregate numerical conversion factor, which is $k=32982 \mathrm{mdeg}$ when $\theta$ is expressed in unit of mdeg, $d$ in $\mathrm{cm}$ and $c$ in mol $\mathrm{dm}^{-3}$. The mean molecular mass of HULIS was assumed to be $280 \mathrm{~g} \mathrm{~mol}^{-1}$ (Kiss et al., 2003; Salma and Láng, 2008), while for the SRFA standard, it was approximated by $836 \mathrm{~g} \mathrm{~mol}^{-1}$ (Salma et al., 2008).

The VCD spectra (difference in the absorbance for the lefthanded circularly polarized light and for the right-handed circularly polarized light as function of wavenumber) and IR absorbance were measured with a Bruker Equinox 55 and PMA37 systems (Germany) in a nitrogen atmosphere using a liquid-nitrogen-cooled mercury-cadmium-telluride (MCT) detector. An optical filter with a transmission range of 1800 $800 \mathrm{~cm}^{-1}$ was applied to optimize the sensitivity of the instrument in the carbonyl and fingerprint regions. The samples were investigated by VCD spectrometry as solid films to avoid the strong absorption band of water at a wavenumber of $1650 \mathrm{~cm}^{-1}$. The measurements were performed in two perpendicular orientations of the window plate for $7 \mathrm{~h}$ each. If the two corresponding spectra were identical to each other within the experimental uncertainty, then the individual spectra were averaged, and the resulting spectrum was used in further evaluations. Baseline correction for the VCD was adopted by subtracting the spectrum recorded for the clear window plate under the identical experimental conditions.

Concentration of organic carbon (OC) in the liquid HULIS samples and filtered aerosol water extracts were measured with a Multi N/C 2100S total organic carbon (TOC) analyzer (Analytik Jena, Germany) in two steps as the difference between total carbon and inorganic carbon. The injection volume was $500 \mu \mathrm{L}$ for both steps, and three replicate injections were carried out. The measured concentration levels were at least two orders above the detection limit for OC, and the relative uncertainty of the mean $\mathrm{OC}$ value calculated from the three individual data was less than $2 \%$. Organic carbon in the 
liquid HULIS samples represents carbon in HULIS (HULIS$\mathrm{C}$ ), while $\mathrm{OC}$ in the aerosol water extracts corresponds to water-soluble organic carbon (WSOC). No correction was applied for sampling artifacts in the present study although it was recognized earlier that both HULIS and WSOC are subject to some positive sampling artifacts in urban and rural aerosol samples collected by high volume samplers (Salma et al., 2007; Maenhaut et al., 2008). Therefore, the corresponding concentration data should be considered as upper limit values. It was also shown that the importance of the artifacts for both HULIS and WSOC decrease with WSOC concentration, and that the correction is below $5 \%$ for WSOC levels above approximately $5 \mu \mathrm{g} \mathrm{m}^{-3}$ for Gelman Pallflex quartz filters. This means that sampling artifacts for both HULIS and WSOC for the biomass burning samples (see the WSOC concentrations in Table 1) can be neglected. It has to be mentioned that evaporation of semi-volatile organics (in particular, for the urban type high-volume aerosol filters) can cause negative sampling artifacts, which can further complicate the quantification. Its magnitude remains uncertain and, furthermore, expedient investigations are needed to address the joint effect.

The organic carbon content of the aerosol samples was determined directly from punches with an area of $1 \mathrm{~cm}^{2}$ of the original quartz filters by the thermal-optical transmission method (Birch and Carry, 1996) using a Sunset Lab (USA).

\section{Results and discussion}

\subsection{OM/OC conversion factor for HULIS from tropical biomass burning}

The OM/OC mass ratio for HULIS is important, since it can be used for converting HULIS-C data experimentally obtained by the TOC method into HULIS mass concentrations. The conversion factor is also a major source of uncertainty in aerosol chemical mass closure calculations involving organics. Conversion factors between 1.2 and 1.6 were proposed for fine atmospheric aerosol in oxidizing (urban) environments, and a factor of $2.1 \pm 0.2$ was suggested for aged (nonurban) aerosol (Turpin and Lim, 2001). For rural and urban environments, OM/OC mass conversion factors specifically for HULIS were determined earlier; they are $1.93 \pm 0.04$ and 1.81, respectively (Kiss et al., 2002; Salma et al., 2007). For biomass burning, the conversion factor was not known. The mass of the pure HULIS samples from biomass burning was large enough even in the aliquot samples (typically between 2 and $3 \mathrm{mg}$ ) as to be weighted with a relative uncertainty below approximately $10 \%$ and with a sufficient reproducibility. Hence, the OM/OC conversion factors for HULIS from tropical biomass burning was estimated by dividing the gravimetric mass by the corresponding HULIS-C data obtained with the TOC method. Mean OM/OC ratio and the standard deviation of $2.04 \pm 0.06$ was derived for both daylight periods and
Table 1. Mean atmospheric concentrations of organic carbon (OC), water-soluble organic carbon (WSOC), carbon in humic-like substances (HULIS-C) and humic-like substances (HULIS) for ru$\mathrm{ral} /$ continental background and urban environments and for a tropical biomass burning impacted site during daylight periods and nights, and the mean contribution of HULIS-C to OC and to WSOC.

\begin{tabular}{|c|c|c|c|c|}
\hline $\begin{array}{l}\text { HULIS type } \\
\text { Constituent [unit] }\end{array}$ & Rural & Urban & $\begin{array}{l}\text { Biomass t } \\
\text { daylight }\end{array}$ & $\begin{array}{r}\text { urning } \\
\text { night }\end{array}$ \\
\hline $\mathrm{OC}\left[\mu \mathrm{g} \mathrm{m}^{-3}\right]$ & n.a. & n.a. & 45 & 66 \\
\hline WSOC $\left[\mu \mathrm{g} \mathrm{m}^{-3}\right]$ & 2.5 & 2.6 & 32 & 37 \\
\hline HULIS-C $\left[\mu \mathrm{g} \mathrm{m}^{-3}\right]$ & 0.86 & 1.24 & 20 & 28 \\
\hline HULIS $\left[\mu \mathrm{g} \mathrm{m}^{-3}\right]$ & $1.65^{\mathrm{a}}$ & $2.2^{\mathrm{a}}$ & $43^{b}$ & $60^{\mathrm{b}}$ \\
\hline HULIS-C/WSOC [\%] & 35 & 48 & 63 & 76 \\
\hline HULIS-C/OC [\%] & $25-48^{\mathrm{c}}$ & $20-28^{\mathrm{d}}$ & 45 & 43 \\
\hline
\end{tabular}

a Calculated from TOC data and OM/OC conversion factors.

$\mathrm{b}$ Derived from gravimetry.

c Adopted from Kiss et al. (2002).

$\mathrm{d}$ adopted from Salma et al. (2007, 2008).

nights based on altogether four sample pairs. The difference between the ratios indicates that the contribution of $\mathrm{C}$ to the HULIS mass changes with the HULIS type, and is likely associated with various formation processes involved in these environments (as outlined in Sect. 1), chemical aging, and the time that is needed for atmospheric reactions to take place.

\subsection{Atmospheric concentration and abundance}

Mean atmospheric concentrations of OC, WSOC, HULIS$\mathrm{C}$ and HULIS for rural and urban environments, and for biomass burning during the daylight periods and nights are given in Table 1. The OC values and the last two WSOC data for the biomass burning site were extracted from a more extensive dataset (cf. Decesari et al., 2006). The concentrations for the rural and urban HULIS are based on the TOC measurements, and the HULIS masses for the biomass burning were derived from gravimetry. All data for the rural and urban sites, and the OC and WSOC values for the biomass burning, are in line with the previous corresponding results (Zappoli et al., 1999; Graham et al., 2002; Kiss et al., 2002; Mayol-Bracero et al., 2002; Samburova et al., 2005a, b; Salma et al., 2007, 2008; Maenhaut et al., 2008). The daily mean HULIS-C concentration for biomass burning of $24 \mu \mathrm{g} \mathrm{m}^{-3}$ is substantially larger than for the mean value for the PA chemical fraction of $6 \pm 5 \mu \mathrm{g} \mathrm{m}^{-3}$ (Mayol-Bracero et al., 2002) and $4.4 \mu \mathrm{g} \mathrm{C} \mathrm{m}{ }^{-3}$ (Decesari et al., 2006) derived from the same sampling site during the dry season in 1999 and 2002, respectively. The difference will be explained by the occurrence of the maximum burning activity over the period represented by the selected samples, as well as by the differences in the separation/isolation protocols applied for 
HULIS and PA. The mean concentration of HULIS increases from the rural environment to the urban environment by a factor of 1.4, while the daily mean concentration of HULIS for the biomass burning impacted site was approximately 30- and 20-times larger than for rural and urban environments, respectively. The mean concentration of WSOC for the biomass burning site was larger by a factor of approximately 13 than for the other two environments. This indicates that biomass burning is an important emission source of or formation mechanism for HULIS with respect to rural and urban environments.

Mean ratios of HULIS-C to WSOC and to OC are also shown in Table 1. Contributions of HULIS-C to WSOC differ significantly for the various sample types, and they increase monotonically for rural, urban and biomass burning samples during daylight periods and nights. Carbon in HULIS for tropical biomass burning represents the major chemical mass fraction of WSOC. The increasing tendency of the HULIS-C/WSOC ratio suggests that some properties of HULIS from the various environments are influenced demonstrably by the differences in their major formation processes. The HULIS-C/OC ratio for the urban sample is somewhat smaller than for the rural and biomass burning samples which is probably related to the smaller share of oxygenated organics in urban environments heavily impacted by vehicular traffic (in the vehicle emissions).

The night-to-daylight period concentration ratios for OC, WSOC and HULIS-C at the biomass burning site were 1.49, 1.15 , and 1.40 , respectively. The larger concentrations during nights were primarily caused by the smaller mixing height of the tropical continental boundary layer which undergoes a diurnal cycle and shows a clear minimum during the night under high pressure meteorological conditions. At the same time, the night-to-daylight period ratio for HULIS$\mathrm{C} / \mathrm{OC}$ was $95 \%$. This implies that contributions of HULIS to OC (and likely their chemical nature) were practically identical during daylight periods and nights, which is also related to the relatively long atmospheric residence time for fine aerosol particles.

\subsection{Electronic circular dichroism}

Absorbance spectra in the UV/Vis and IR ranges for HULIS were presented, analysed, and discussed earlier (e.g., Zappoli et al., 1999; Krivácsy et al., 2001; Kiss et al., 2002; Duarte et al., 2005) mainly with the purpose of comparing HULIS to humic or fulvic acids, or for identifying some chemical functional groups within HULIS. In the present work, relevant parts of the spectra are shown for different types of HULIS primarily to examine their variance, and to discuss its consequences for optical activity and chromophores. The absorbance spectra of HULIS obtained from biomass burning over daylight periods, rural and urban aerosols, and of the SRFA standard in the UV wavelength interval of 190280 and 260-400 nm are shown in Fig. 1a and b, respectively.
The spectra for HULIS in Fig. 1a were measured in a cuvette with a path length of $0.02 \mathrm{~cm}$, while the curves in Fig. $1 \mathrm{~b}$ were obtained in a cuvette with a path length of $0.2 \mathrm{~cm}$. The dissolved HULIS-C concentrations were approximately $0.52,0.36,0.20 \mathrm{~g} \mathrm{~L}^{-1}$ for the rural, urban and biomass burning HULIS, respectively. For the SRFA standard, a cuvette with a path length of $0.2 \mathrm{~cm}$ was only used, and the dissolved concentrations in Fig. $1 \mathrm{a}$ and $\mathrm{b}$ were 0.17 and $0.3 \mathrm{~g} \mathrm{~L}^{-1}$, respectively. It is seen that the spectra of HULIS are rather similar to each other in the whole region; in particular, the shape of the curves for the biomass burning and rural HULIS in Fig. 1a are close to each other. The UV absorbance spectra essentially have a featureless shape and are also similar to those observed earlier. The curves exhibit a maximum at the far end of the wavelength interval and they are shifted toward larger wavelength values in the order of the samples: urban, rural, biomass burning HULIS and SRFA. The intensity in the curves decreases almost monotonically with wavelength. There is only a small shoulder on the curves in the region of $245-275 \mathrm{~nm}$, which is also shifted to larger wavelength values in the order of the sample set listed above. The maxima in both regions are explained by the absorption of the aromatic rings. Their red shift can be caused by increasing abundance of polar (oxygenated) substituents on the aromatic rings with respect to non-polar substituents, which is inferred from the increasing molar $\mathrm{O} / \mathrm{C}$ and WSOC/OC ratios derived for this sample set (Kiss et al., 2002; Mayol-Bracero et al., 2002; Salma et al., 2004; see also Sect. 3.4), and from the concept of aerosol aging (Fuzzi et al., 2006).

Figure $2 \mathrm{a}$ and $\mathrm{b}$ show the ECD spectra in the wavelength ranges of 200-280 and 260-400 nm, respectively for HULIS obtained from the biomass burning over daylight periods (panel a), rural (panel b) and urban aerosols (panel c), and for the SRFA standard (panel d). The thinner lines represent the measured data, and the thicker lines were obtained by $10-\mathrm{nm}$ smoothing. The experimental uncertainty interval for the baseline of the differential molar extinction coefficient depends on the actual measurement setup of the instrument, cuvette characteristics, and on the optical properties of the sample measured. Considering these properties, the ECD spectra in Fig. 2a and b were not normalized to dissolved $\mathrm{C}$ concentration. The yellow colour of the solutions further hindered the adjustment of the optimal signal-to-noise ratio. The uncertainty interval of the baseline was estimated for each measurement, and it is also shown in the panels by the grey area. All measured and smoothed curves in Fig. 2a lay within the uncertainty interval of the baseline; moreover, the smoothed curves show no tendency. The curves in Fig. $2 b$ also fall within the experimental uncertainty interval of the baseline except for the rural HULIS (panel b in Fig. 2) which is just above the limit. Moreover, the spectrum for the rural HULIS differs from all the other curves in that it seems to reveal some regular change, an ECD band in the interval of $300-335 \mathrm{~nm}$. The available spare amount of the rural HULIS, unfortunately, did not make it feasible to prepare a 

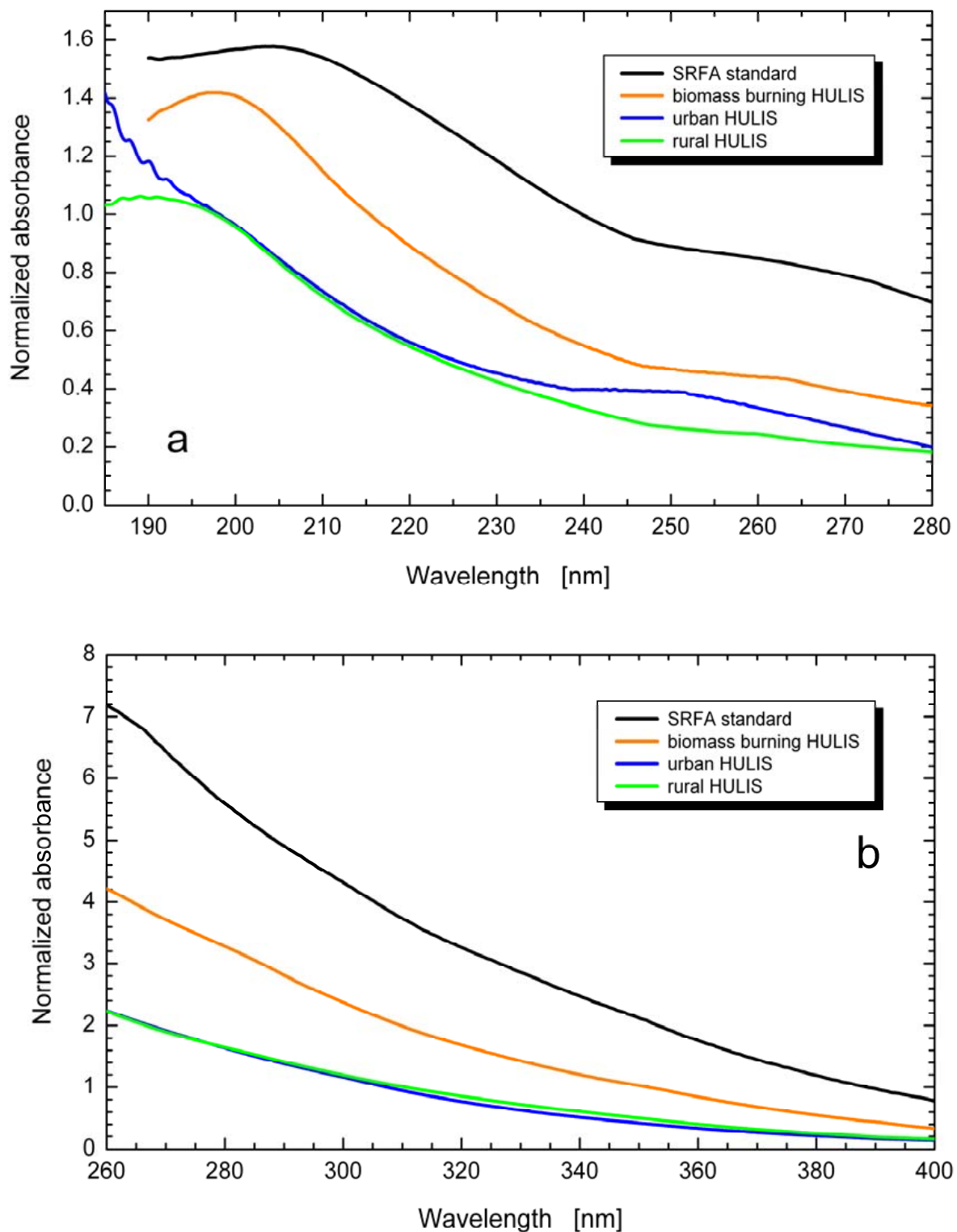

Fig. 1. UV absorbance spectra for HULIS isolated from tropical biomass burning, rural and urban aerosols, and for the Suwannee River Fulvic Acid (SRFA) standard normalized to the concentration of dissolved carbon for the wavelength range of 190-280 nm (a) and 260$400 \mathrm{~nm}$ (b).

more concentrated solution to examine the concentration dependence on the band. We could only record another spectrum for the same solution in a cuvette with a smaller path length of $0.1 \mathrm{~cm}$. The two corresponding smoothed curves showed a similar shape with an amplitude in the specified interval that was smaller for the smaller cuvette. The band may be associated with HULIS formed from chiral precursor VOCs, e.g., biogenic monoterpenes with one of their enantiomers slightly enriched. Nevertheless, it has to be noted that the absolute extent of the optical activity is rather small in comparison to ordinary optically active compounds.
The other spectra do not necessarily mean that HULIS, from all investigated environments and the SRFA standard, are achiral. To be optically active, a molecule must be structurally asymmetric and exhibit absorbance. It is possible that HULIS do contain chiral centres but these do not exhibit considerable absorbance in the studied range. Other aliquots of the samples were, therefore, investigated further by a complementary method, VCD spectrometry. In this regard, it is also worth mentioning that levoglucosan, as the major single product of the cellulose thermal degradation, is chiral; however, it lacks chromophores and, therefore, it does not 
$2 \mathrm{a}$

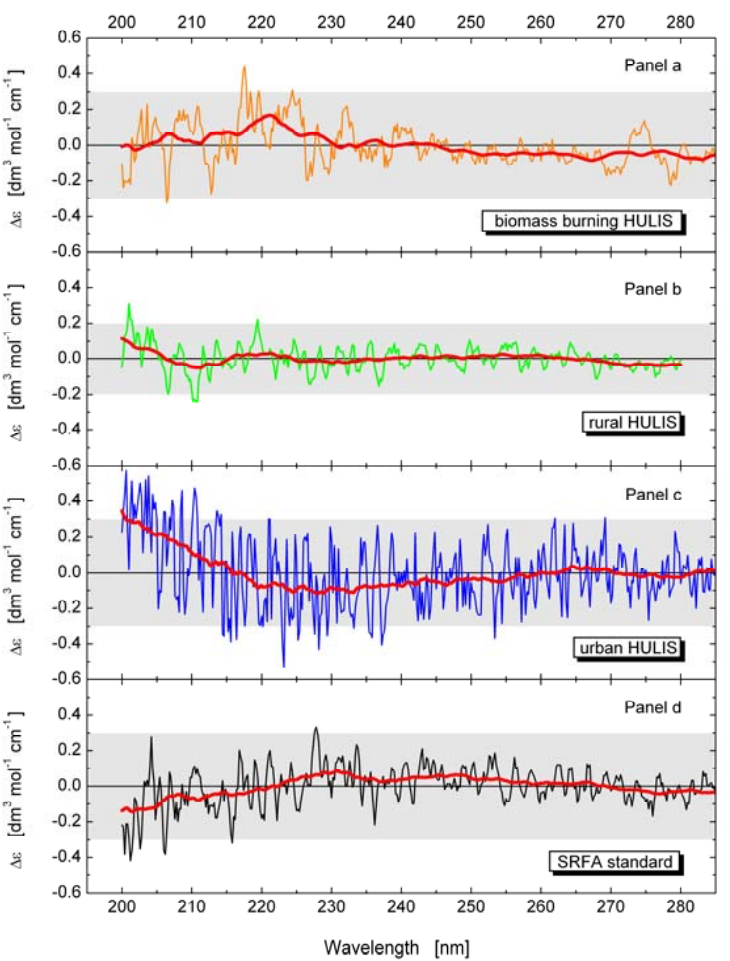

$2 \mathrm{~b}$

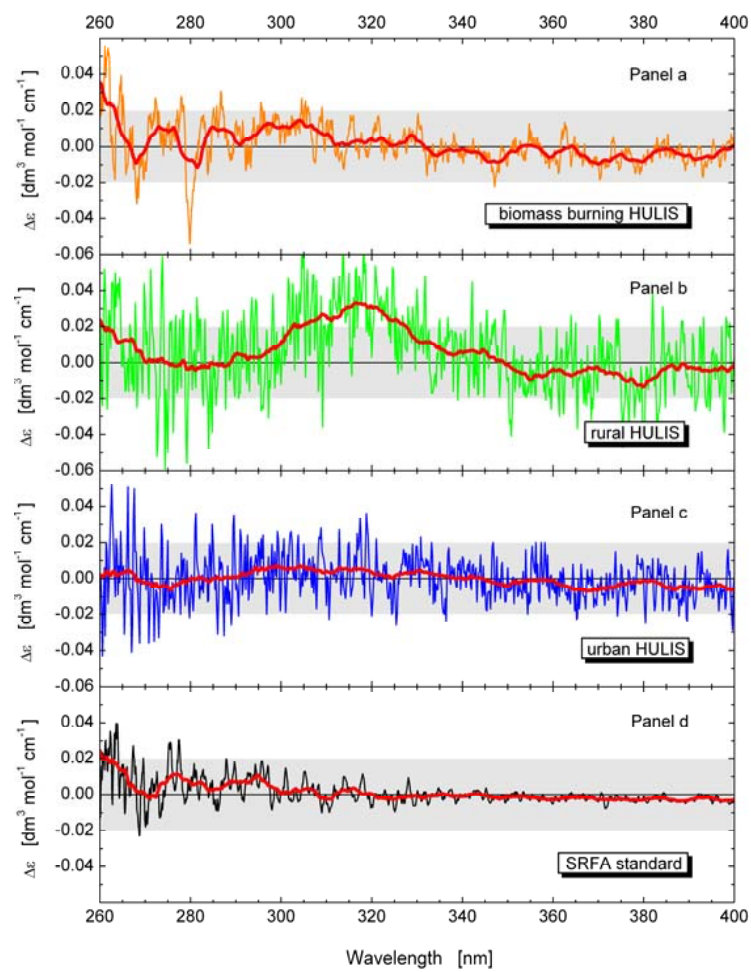

Fig. 2. Electronic circular dichroism spectra in the wavelength ranges of 200-280 nm (a) and 260-400 nm (b) for HULIS isolated from tropical biomass burning (panel a), rural (panel b) and urban (panel c) aerosols, and for the Suwannee River Fulvic Acid (SRFA) standard (panel d). The thinner lines are the measured data, and the thicker (red) lines were obtained by 10-nm smoothing. The uncertainty interval of the baseline is shown by the grey area. Concentrations of the dissolved C for the various spectra are given in Sect. 3.3.

generate ECD bands, and also, it is not expected to appear in the isolated chemical fraction.

\subsection{Vibrational circular dichroism}

Absorbance of HULIS obtained from biomass burning over daylight periods, rural and urban aerosols, and the SRFA standard in the IR range for the wavenumber interval from 1800 to $1000 \mathrm{~cm}^{-1}$ that is covered by the VCD spectrometry, is shown in Fig. 3. The curves were not normalized to the dissolved $\mathrm{C}$ concentration since its actual value in the solid samples were only know with larger uncertainty due to the sample preparation procedure described in Sect. 2.1, and since it is the IR absorbance that was optimized. The spectra exhibit relatively few, broad bands and are comparable to those observed earlier (see Refs. in Sect. 3.3). The curves are also similar to each other for the various HULIS types. The similarity between the rural and urban HULIS is greater than between them and biomass burning HULIS. Some apparent differences are the following: (1) The absorption band near $1730 \mathrm{~cm}^{-1}$ (attributed to $\mathrm{C}=\mathrm{O}$ stretching for carboxylic acid) is larger for biomass burning than for the other two environments. The larger intensity of the band for the biomass burning indicates a larger abundance of the carbonyl functional group, or its different position with respect to the aromatic ring(s). Interestingly, the bands for the other two types of HULIS are almost identical despite the fact that urban HULIS (with a molar O/C ratio of 0.47; Salma et al., 2007) are less oxidized than rural HULIS (with a molar O/C ratio of 0.58 , Kiss et al., 2002); (2) The band in the $1600-1650 \mathrm{~cm}^{-1}$ region appears at smaller values for biomass burning HULIS likely due to differences in the chemical environment for the various types of HULIS; (3) The band at approximately $1520 \mathrm{~cm}^{-1}$ appears in the spectrum for the biomass burning while it is missing from the other two spectra. The later two absorption bands are related to the skeletal vibrations of the aromatic rings and are influenced by functional groups linked to the rings. Both bands appear markedly in the IR spectra of lignins and their derivates (Petrovic et al., 2004) which suggests that lignins or their degradation products contribute remarkably to the HULIS formation in biomass burning; (4) The absorption band at $1280 \mathrm{~cm}^{-1}$ (assigned to the $\mathrm{C}-\mathrm{O}$ stretching of methoxy-substituted aromatic rings and/or $\mathrm{OH}$ bending vibrations of $\mathrm{COOH}$ groups) is less evident for biomass burning than for the other two environments. The IR 


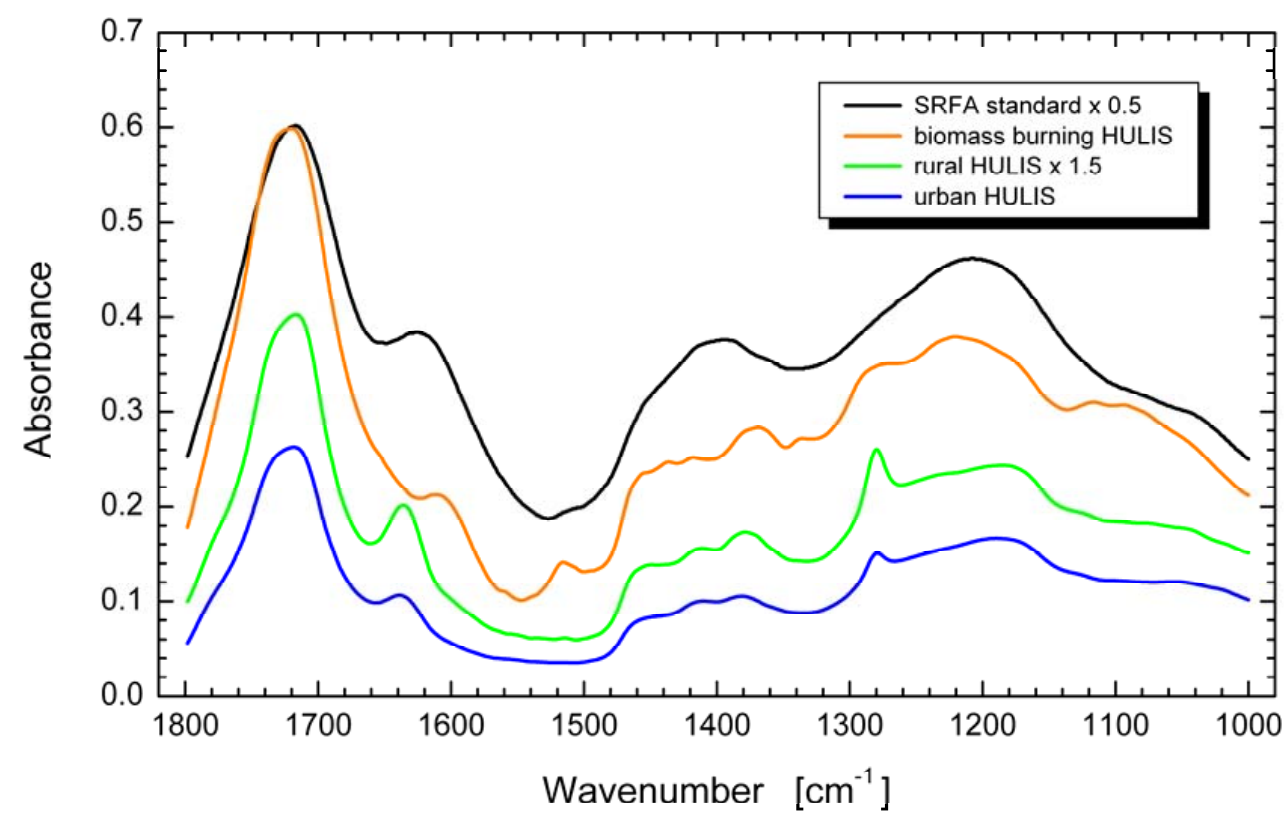

Fig. 3. IR absorbance spectra for HULIS samples isolated from urban, rural and tropical biomass burning aerosols, and for the Suwannee River Fulvic Acid (SRFA) standard in the wavenumber range of $1800-1000 \mathrm{~cm}^{-1}$.

absorption bands for biomass burning HULIS are generally broader, which indicates that biomass burning HULIS are a more complex mixture than the other two types. Interestingly, the absorbance spectrum of biomass burning HULIS agrees better with the spectrum of SRFA standard in several aspects than with that for the other two HULIS types. This might be related to the fact that both biomass burning HULIS and SRFA have a common origin in the plant material though they were generated by different decomposing processes, i.e., by thermal degradation and anaerobic biodegradation (or humification), respectively.

Figure 4 shows the VCD spectra of HULIS obtained from the tropical biomass burning over daylight periods, rural and urban aerosols in the wavenumber range of 1800 $1000 \mathrm{~cm}^{-1}$. It is seen that rural and urban HULIS showed practically no optical activity in the whole range. HULIS from biomass burning, however, shows a huge negative VCD band near $1730 \mathrm{~cm}^{-1}$, which is related to the large absorption band (vibration of carbonyl functional group in carboxylic acid) shown in Fig. 3. This means that the considerable abundance of the carboxyl group in biomass burning HULIS is in a chiral chemical environment, which is a clear distinction from the other two HULIS types. The chiral environment can be associated with the cellulose degradation products. The huge VCD band of the biomass burning HULIS was checked by using a different optical filter that optimizes the performance of the instrument in the carbonyl region. The shape and intensity of the band also indicated that it represents a real effect. Unlike the HULIS thin samples, the SRFA film prepared for the VCD measurement formed an oriented anisotropic film which led to linear dichroism artifacts. It means that the shape of the VCD spectra recorded in two perpendicular orientations strongly differed from each other and, therefore, valuable conclusions on the optical activity of the SRFA standard could not be drawn from the solid sample.

\section{Conclusions}

The atmospheric concentrations and abundances of watersoluble HULIS in various environments imply that important emission sources or formation mechanisms of HULIS operate in biomass burning environments when compared to rural/continental background and urban sites. Differentiation among the possible formation processes was attempted by investigating the optical activity of various HULIS types. Circular dichroism - applied, to our knowledge, for the first time in aerosol research - together with isolation methods were shown to be valuable accessory tools for investigating organic constituents. The urban HULIS did not show optical activity in both ECD and VCD spectrometry, which is in line with the concept of their airborne formation mainly from anthropogenic aromatics. The rural HULIS revealed weak optical activity in the ECD spectrometry and no effect in the VCD, which may be associated with one of their important formation pathways by photo-oxidation and oligomerisation, i.e., with the formation from chiral precursor VOCs, e.g., biogenic monoterpenes with one of their enantiomers slightly enriched. Biomass burning HULIS exhibited no activity in the ECD spectrometry and a strong VCD band, which was 


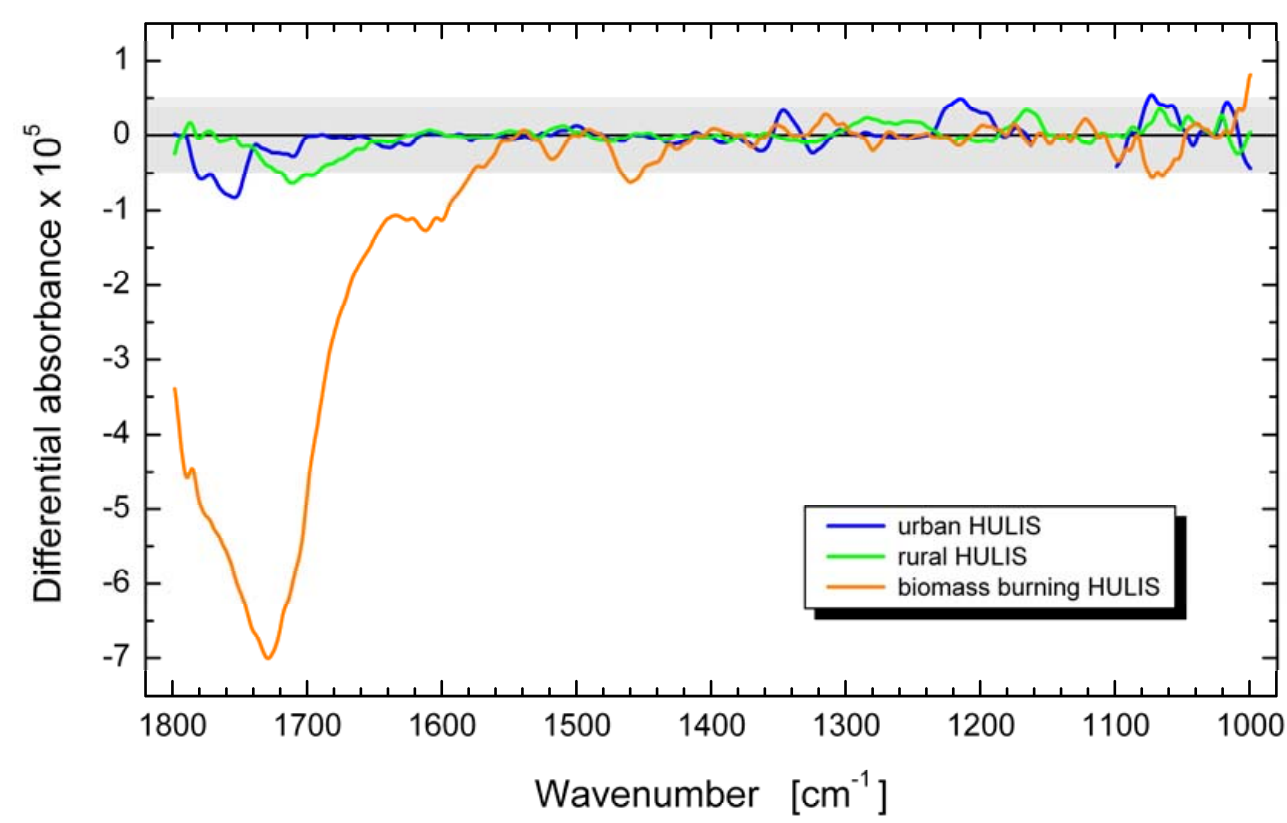

Fig. 4. Vibrational circular dichroism spectra for HULIS samples isolated from urban, rural and tropical biomass burning aerosols in the wavenumber range of $1800-1000 \mathrm{~cm}^{-1}$. The uncertainty interval of the baseline is shown by the grey area.

interpreted - together with their IR absorbance - as the contribution of thermal degradation products of lignins and cellulose.

Substantial absorbance values observed in the UV and IR ranges imply that the bulk amount of HULIS present in the samples was sufficient for observing optical activity. In the VCD spectrometry, the intensity of the VCD signal is usually between $10^{-5}-10^{-4}$ of the IR absorbance, which means that the differential absorbance was expected to be above the noise level and baseline uncertainty. The upper concentration was limited by a value of approximately $1 \mathrm{~g} \mathrm{~L}^{-1}$ above which HULIS can form aggregates (Tabazadeh, 2005; Salma et al., 2008), and which are undesirable in the ECD spectrometry. As far as individual compounds are concerned, it cannot be excluded that some of them were not observed because of their small amount and weak optical activity.

It has also to be noted that the conclusions are based on a limited number of samples and, therefore, the topic definitely needs further experimental studies. In addition, the achievements of the method can also be improved in future studies by further optimising, modifying and extending the procedures presented.
Acknowledgements. The financial support of the Hungarian Scientific Research Fund (contract K61193) and of the Economic Competitiveness Operational Program (contract GVOP-3.2.12004-04-0345/3.0) is appreciated. One of us (W. M.) acknowledges the financial support from the Belgian Federal Science Policy Office and the "Fonds voor Wetenschappelijk Onderzoek - Vlaanderen". The authors thank A. Hoffer and G. Kiss of the University of Pannonia for collecting the aerosol samples at the K-puszta.

Edited by: F. Keutsch

\section{References}

Asa-Awuku, A., Sullivan, A. P., Hennigan, C. J., Weber, R. J., and Nenes, A.: Investigation of molar volume and surfactant characteristics of water-soluble organic compounds in biomass burning aerosol, Atmos. Chem. Phys., 8, 799-812, 2008, http://www.atmos-chem-phys.net/8/799/2008/.

Baltensperger, U., Kalberer, M., Dommen, J., Paulsen, D., Alfarra, M. R., Coe, H., Fisseha, R., Gascho, A., Gysel, M., Nyeki, S., Sax, M., Steinbacher, M., Prevot, A. S. H., Sjögren, S., Weingartner, E., and Zenobi, R.: Secondary organic aerosols from anthropogenic and biogenic precursors, Faraday Discuss., 130, 265-278, 2005.

Birch, M. E. and Cary, R. A.: Elemental carbon-based method for monitoring occupational exposures to particulate diesel exhaust, Aerosol Sci. Tech., 25, 221-241, 1996.

Blazsó, M., Janitsek, S., Gelencsér, A., Artaxo, P., Graham, B., and Andreae, M. O.: Study of tropical organic aerosol by thermally assisted alkylation-gas chromatography mass spectrometry, J. Anal. Appl. Pyrol., 68-69, 351-369, 2003. 
Claeys, M., Graham, B., Vas, G., Wang, W., Vermeylen, R., Pashynska, V., Cafmeyer, J., Guyon, P., Andreae, M. O., Artaxo, P., and Maenhaut, W.: Formation of secondary organic aerosols through photooxidation of isoprene, Science, 303, 1173-1176, 2004a.

Claeys, M., Wang, W., Ion, A. C., Kourtchev, I., Gelencsér, A., and Maenhaut, W.: Formation of secondary organic aerosols from isoprene and its gas-phase oxidation products through reaction with hydrogen peroxide, Atmos. Environ., 38, 4093-4098, 2004b.

Decesari, S., Facchini, M. C., Fuzzi, S., and Tagliavini, E.: Characterisation of water-soluble organic compounds in atmospheric aerosol: a new approach, J. Geophys. Res., 105, 1481-1489, 2000

Decesari, S., Facchini, M. C., Matta, E., Mircea, M., Fuzzi, S., Chughtai, A. R., and Smith, D. M.: Water soluble organic compounds formed by oxidation of soot, Atmos. Environ., 36, 18271832, 2002.

Decesari, S., Fuzzi, S., Facchini, M. C., Mircea, M., Emblico, L., Cavalli, F., Maenhaut, W., Chi, X., Schkolnik, G., Falkovich, A., Rudich, Y., Claeys, M., Pashynska, V., Vas, G., Kourtchev, I., Vermeylen, R., Hoffer, A., Andreae, M. O., Tagliavini, E., Moretti, F., and Artaxo, P.: Characterization of the organic composition of aerosols from Rondnia, Brazil, during the LBASMOCC 2002 experiment and its representation through model compounds, Atmos. Chem. Phys., 6, 375-402, 2006, http://www.atmos-chem-phys.net/6/375/2006/.

Dinar, E., Taraniuk, I., Graber, E. R., Katsman, S., Moise, T., Anttila, T., Mentel, T. F., and Rudich, Y.: Cloud Condensation Nuclei properties of model and atmospheric HULIS, Atmos. Chem. Phys., 6, 2465-2482, 2006,

http://www.atmos-chem-phys.net/6/2465/2006/.

Dinar, E., Riziq, A. A., Spindler, C., Erlick, C., Kiss, G., and Rudich, Y.: The complex refractive index of atmospheric and model humic-like substances (HULIS) retrieved by a cavity ring down aerosol spectrometer (CRD-AS), Faraday Discuss., 137, 279-295, 2008.

Duarte, R., Pio, C. A., and Duarte, A. C.: Spectroscopic study of the water-soluble organic matter isolated from atmospheric aerosols collected under different atmospheric conditions, Anal. Chim. Acta, 530, 7-14, 2005.

Emmenegger, C., Reinhardt, A., Hueglin, C., Zenobi, R., and Kalberer, M.: Evaporative light scattering: A novel detection method for the quantitative analysis of humic-like substances in aerosols, Environ. Sci. Technol., 41, 2473-2478, 2007.

Facchini, M. C., Mircea, M., Fuzzi, S., and Charlson, R. J.: Cloud albedo enhancement by surface-active organic solutes in growing droplets, Nature, 401, 257-259, 1999.

Facchini, M. C., Decesari, S., Mircea, M., Fuzzi, S., and Loglio, G: Surface tension of atmospheric wet aerosol and cloud/fog droplets in relation to their organic carbon content and chemical composition, Atmos. Environ., 34, 4853-4857, 2000.

Fuzzi, S., Andreae, M. O., Huebert, B. J., Kulmala, M., Bond, T. C., Boy, M., Doherty, S. J., Guenther, A., Kanakidou, M., Kawamura, K., Kerminen, V.-M., Lohmann, U., Russell, L. M., and Pöschl, U.: Critical assessment of the current state of scientific knowledge, terminology, and research needs concerning the role of organic aerosols in the atmosphere, climate, and global change, Atmos. Chem. Phys., 6, 2017-2038, 2006,

http://www.atmos-chem-phys.net/6/2017/2006/.
Gao, S., Keywood, M., Ng, N. L., Surratt, J., Varutbangkul, V., Bahreini, R., Flagan, R. C., and Seinfeld, J. H.: Low-molecularweight and oligomeric components in secondary organic aerosol from the ozonolysis of cycloalkenes and $\alpha$-pinene, J. Phys. Chem. A, 108, 10147-10164, 2004.

Gelencsér, A., Hoffer, A., Kiss, G., Tombácz, E., Kurdi, R., and Bencze, L.: In-situ formation of light-absorbing organic matter in cloud water, J. Atmos. Chem., 45, 25-33, 2003.

Graber, E. R. and Rudich, Y.: Atmospheric HULIS: How humiclike are they? A comprehensive and critical review, Atmos. Chem. Phys., 6, 729-753, 2006,

http://www.atmos-chem-phys.net/6/729/2006/.

Graham, B., Mayol-Bracero, O. L., Guyon, P., Roberts, G. C., Decesari, S., Facchini, M. C., Artaxo, P., Maenhaut, W., Köll, P., and Andreae, M. O.: Water-soluble organic compounds in biomass burning aerosol over Amazonia, 1. Characterisation by NMR and GC-MS, J. Geophys. Res., 107(D20), 8047, doi:10.1029/2001JD000336, 2002.

Guenther, A., Hewitt, C. N., Erickson, D., Fall, R., Geron, C., Graedel, T., Harley, P., Klinger, V., Lerdau, M., McKay, W. A., Pierce, T., Scholes, B., Steinbreacher, R., Tallamraju, R., Taylor, J., and Zimmerman, P.: A global model of natural volatile organic compound emissions, J. Geophys. Res., 100, 8873-8892, 1995.

Hoffer, A., Kiss, G., Blazsó, M., and Gelencsér, A.: Chemical characterization of humic-like substances (HULIS) formed from a lignin-type precursor in model cloud water, Geophys. Res. Lett., 31, L06115, doi:10.1029/2003GL018962, 2004.

Hoffmann, T. and Warnke, J.: Organic Aerosols, in: Volatile Organic Compounds in the Atmosphere, in: Volatile organic compounds in the atmosphere, edited by: Koppmann, R., Blackwell Publishing, Oxford, 342-387, 2007.

Iinuma, Y., Böge, O., Gnauk, T., and Herrmann, H.: Aerosolchamber study of the $\alpha$-pinene $/ \mathrm{O}_{3}$ reaction: influence of particle acidity on aerosol yields and products, Atmos. Environ., 38, 761-773, 2004

Jang, M., Czoschke, N. M., Lee, S., and Kamens, R. M.: Heterogeneous atmospheric aerosol production by acid-catalyzed particlephase reactions, Science, 298, 814-817, 2002.

Kalberer, M., Paulsen, D., Sax, M., Steinbacher, M., Dommen, J., Prevot, A. S. H., Fisseha, R., Weingartner, E., Frankevich, V., Zenobi, R., and Baltensperger, U.: Identification of polymers as major components of atmospheric organic aerosols, Science, 303, 1659-1662, 2004.

Kiss, G., Varga, B., Galambos, I., and Ganszky, I.: Characterization of water-soluble organic matter isolated from atmospheric fine aerosol, J. Geophys. Res., 107(D21), 8339, doi:10.1029/2001JD000603, 2002.

Kiss, G., Tombácz, E., Varga, B., Alsberg, T., and Persson, L.: Estimation of the average molecular weight of humic-like substances isolated from fine atmospheric aerosol, Atmos. Environ., 37, 3783-3794, 2003.

Kiss, G., Tombácz, E., and Hansson, H.-C.: Surface tension effects of humic-like substances in the aqueous extract of troposphere fine aerosol, J. Atmos. Chem., 50, 279-294, 2005.

Kroll, J. H. and Seinfeld, J. H.: Chemistry of secondary organic aerosol: Formation and evolution of low-volatility organics in the atmosphere, Atmos. Environ., 42, 3593-3624, 2008. 
Krivácsy, Z., Gelencsér, A., Kiss, G., Mészáros, E., Molnár, A., Hoffer, A., Mészáros, T., Sárvári, Z., Temesi, D., Varga, B., Baltensperger, U., Nyeki, S., and Weingartner, E.: Study on the chemical character of water soluble organic compounds in fine atmospheric aerosol at the Jungfraujoch, J. Atmos. Chem., 39, 235-259, 2001.

Limbeck, A. and Puxbaum, H.: Organic acids in continental background aerosols, Atmos. Environ., 33, 1847-1852, 1999.

Limbeck, A., Kulmala, M., and Puxbaum, H.: Secondary organic aerosol formation in the atmosphere via heterogeneous reaction of gaseous isoprene on acidic particles, Geophys. Res. Lett., 30(19), 1996, doi:10.1029/2003GL017738, 2003.

Limbeck, A., Handler, M., Neuberger, B., Klatzer, B., and Puxbaum, H.: Carbonspecific analysis of humic-like substances in atmospheric aerosol and precipitation samples, Anal. Chem., 77, 7288-7293, 2005.

Maenhaut, W., Raes, N., Chi, X., Cafmeyer, J., and Wang, W.: Chemical composition and mass closure for $\mathrm{PM}_{2.5}$ and $\mathrm{PM}_{10}$ aerosols at K-puszta, Hungary, in summer 2006, X-Ray Spectrom., 37, 193-197, 2008.

Mayol-Bracero, O. L., Guyon, P., Graham, B., Roberts, G., Andreae, M. O., Decesari, S., Facchini, M. C., Fuzzi, S., and Artaxo, P.: Water-soluble organic compounds in biomass burning aerosols over Amazonia, 2. Apportionment of the chemical composition and importance of the polyacidic fraction, J. Geophys. Res., 107(D20), 8091, doi:10.1029/2001JD000522, 2002.

Nunes, F. M. N., Veloso, M. C. C., Pereira, P. A. D. P., and de Andrade, J. B.: Gas-phase ozonolysis of the monoterpenoids (S)(+)-carvone, (R)-(-)-carvone, (-)-carveol, geraniol and citral, Atmos. Environ., 39, 7715-7730, 2005.

Petrovic, A. G., Bose, P. K., and Polavarapu, P. L.: Vibrational circular dichroism of carbohydrate films formed from aqueous solutions, Carbohyd. Res., 339, 2713-2720, 2004.

Ralph, J., Peng, J., Lu, F., Hatfield, R. D., and Helm, R. F.: Are lignins optically active?, J. Agr. Food Chem., 47, 2991-2996, 1999.

Salma, I., Chi, X., and Maenhaut, W.: Elemental and organic carbon in urban canyon and background environments in Budapest, Hungary, Atmos. Environ., 38, 27-36, 2004.

Salma, I., Ocskay, R., Varga, I., and Maenhaut, W.: Surface tension of atmospheric humic-like substances in connection with relaxation, dilution, and solution pH, J. Geophys. Res., 111, D23205, doi:10.1029/2005JD007015, 2006.

Salma, I., Ocskay, R., Chi, X., and Maenhaut, W.: Sampling artefacts, concentrations and chemical composition of fine watersoluble organic carbon and humic-like substances in a continental urban atmospheric environment, Atmos. Environ., 41, 41064118, 2007.

Salma, I., Ocskay, R., and Láng, G. G.: Properties of atmospheric humic-like substances - water system, Atmos. Chem. Phys., 8, 2243-2254, 2008, http://www.atmos-chem-phys.net/8/2243/2008/.

Salma, I. and Láng, G. G.: How many carboxyl groups does an average molecule of humic-like substances contain?, Atmos. Chem. Phys., 8, 5997-6002, 2008, http://www.atmos-chem-phys.net/8/5997/2008/.
Samburova, V., Zenobi, R., and Kalberer, M.: Characterization of high molecular weight compounds in urban atmospheric particles, Atmos. Chem. Phys., 5, 2163-2170, 2005, http://www.atmos-chem-phys.net/5/2163/2005/.

Samburova, V., Szidat, S., Hueglin, C., Fisseha, R., Baltensperger, U., Zenobi, R., and Kalberer, M.: Seasonal variation of high-molecular-weight compounds in the water-soluble fraction of organic urban aerosols, J. Geophys. Res., 110, D23210, doi:10.1029/2005JD005910, 2005b.

Saxena, P. and Hildemann, L. M.: Water-soluble organics in atmospheric particles: A critical review of the literature and application of thermodynamics to identify candidate compounds, J. Atmos. Chem., 24, 57-109, 1996.

Schauer, J. J., Kleeman, M. J., Cass, G. R., and Simoneit, B. R. T.: Measurement of emissions from air pollution sources, 3. $\mathrm{C}_{1}-\mathrm{C}_{29}$ organic compounds from fireplace combustion of wood, Environ. Sci. Technol., 35, 1716-1728, 2001.

Simoneit, B. R. T., Schauer, J. J., Nolte, C. G., Oros, D. R., Elias, V. O., Fraser, M. P., Rogge, W. F., and Cass, G. R.: Levoglucosan, a tracer for cellulose in biomass burning and atmospheric particles, Atmos. Environ., 33, 173-182, 1999.

Stone, E. A., Hedman, C. J., Sheesley, R. J., Shafer, M. M., and Schauer, J. J.: Investigating the chemical nature of humic-like substances (HULIS) in North American atmospheric aerosols by liquid chromatography tandem mass spectrometry, Atmos. Environ., 43, 4205-4213, 2009.

Tabazadeh, A.: Organic aggregate formation in aerosols and its impact on the physicochemical properties of atmospheric particles, Atmos. Environ., 39, 5472-5480, 2005.

Topping, D. O., McFiggans, G. B., Kiss, G., Varga, Z., Facchini, M. C., Decesari, S., and Mircea, M.: Surface tensions of multicomponent mixed inorganic/organic aqueous systems of atmospheric significance: measurements, model predictions and importance for cloud activation predictions, Atmos. Chem. Phys., 7, 2371-2398, 2007, http://www.atmos-chem-phys.net/7/2371/2007/.

Turpin, B. J. and Lim, H.-J.: Species contributions to $\mathrm{PM}_{2.5}$ mass concentrations: revisiting common assumptions for estimating organic mass, Aerosol Sci. Tech., 35, 602-610, 2001.

Varga, B., Kiss, G., Ganszky, I., Gelencsér, A., and Krivácsy, Z.: Isolation of water soluble organic matter from atmospheric aerosol, Talanta, 55, 561-572, 2001.

Varga, Z., Kiss, G., and Hansson, H.-C.: Modelling the cloud condensation nucleus activity of organic acids on the basis of surface tension and osmolality measurements, Atmos. Chem. Phys., 7, 4601-4611, 2007, http://www.atmos-chem-phys.net/7/4601/2007/.

Wex, H., Hennig, T., Salma, I., Ocskay, R., Kiselev, A., Henning, S., Massling, A., Wiedensohler, A., and Stratmann, F.: Hygroscopic growth and measured and modeled critical supersaturations of an atmospheric HULIS sample, Geophys. Res. Lett., 34, L02818, doi:10.1029/2006GL028260, 2007.

Williams, J., Yassaa, N., Bartenbach, S., and Lelieveld, J.: Mirror image hydrocarbons from Tropical and Boreal forests, Atmos. Chem. Phys., 7, 973-980, 2007, http://www.atmos-chem-phys.net/7/973/2007/. 
Zappoli, S., Andracchio, A., Fuzzi, S., Facchini, M. C., Gelencsér, A., Kiss, G., Krivácsy, Z., Molnár, A., Mészáros, E., Hansson, H. C., and Rosman, K.: Inorganic, organic and macromolecular components of fine aerosol in different areas of Europe in relation to their water solubility, Atmos. Environ., 33, 2733-2743, 1999.
Ziese, M., Wex, H., Nilsson, E., Salma, I., Ocskay, R., Hennig, T., Massling, A., and Stratmann, F.: Hygroscopic growth and activation of HULIS particles: experimental data and a new iterative parameterization scheme for complex aerosol particles, Atmos. Chem. Phys., 8, 1855-1866, 2008,

http://www.atmos-chem-phys.net/8/1855/2008/. 